Board of Governors of the Federal Reserve System

International Finance Discussion Papers

Number 592

October 1997

\title{
ROADS TO PROSPERITY? \\ ASSESSING THE LINK BETWEEN PUBLIC CAPITAL AND PRODUCTIVITY
}

\author{
John Fernald
}

NOTE: International Finance Discussion Papers are preliminary materials circulated to stimulate discussion and critical comment. References in publications to International Finance Discussion Papers (other than an acknowledgment that the writer has had access to unpublished material) should be cleared with the author or authors. Recent IFDPs are available on the Web at www.bog.frb.fed.us. 


\title{
ROADS TO PROSPERITY? \\ ASSESSING THE LINK BETWEEN PUBLIC CAPITAL AND PRODUCTIVITY
}

\author{
John Fernald*
}

\begin{abstract}
At a macroeconomic level, infrastructure and productivity are positively correlated in the United States and other countries. However, it remains unclear whether this correlation reflects causation, and if so, whether causation runs from infrastructure to productivity, or the reverse. This paper focuses on roads, and finds that vehicle-intensive industries benefit disproportionately from road-building: when road growth changes, productivity growth changes more in industries that are more vehicle intensive. These results suggest that causation runs from infrastructure to productivity. However, there is no evidence that at the margin, roads offer an above-average return; road-building in essence offered a one-time boost to the level of productivity in the 1950s and 1960s. Finally, it appears that congestion significantly affects road-services at the margin, although congestion does not appear important before 1973.
\end{abstract}

* Fernald is an economist in the International Finance Division of the Federal Reserve Board, and can be contacted at fernaldj@frb.gov. An earlier version of this paper, entitled "How Productive is Infrastructure?", was Chapter 2 of my 1993 Harvard Ph.D. thesis. I thank Robert Barro, Susanto Basu, David Cutler, Brad De Long, Andy Levin, Ben Polak, and, especially, Charles Hulten, Dale Jorgenson, and Greg Mankiw for helpful discussions and comments. I also thank several anonymous referees and seminar participants at a number of universities and institutions who provided feedback. The views in this paper are solely the responsibility of the author and should not be interpreted as reflecting the views of the Board of Governors of the Federal Reserve System or of any other person associated with the Federal Reserve System. 
Recent macroeconomic literature documents a strong correlation between infrastructure and productivity in the United States and other western economies. However, it remains unclear how to interpret this correlation. Some authors argue that infrastructure provides highly valuable services to the private sector, and that the slowdown in public investment after the early 1970s explains a substantial portion of the widely noted productivity slowdown, which occurred around the same time. By contrast, other authors argue that public capital is endogenous, so that causation runs from productivity to public investment, or that the correlation is completely spurious, reflecting a misspecification of trend. ${ }^{1}$

This paper explores the interpretation of this correlation by focusing on roads, the largest component of public capital. In 1994 , the value of the road stock was $\$ 1.2$ trillion, worth nearly a quarter of private business GDP. Indeed, in the 1950s and 1960s, road-building accounted for a substantial fraction of capital formation in the United States, with net investment exceeding a quarter of the value of net non-residential private investment. As shown in Figure 1, road growth slowed substantially after the early 1970s, and in per capita terms the stock has changed little since then.

I ask how changes in roads affect the relative productivity performance of U.S. industries from 1953 to 1989 . If roads are productive, then industries that use roads intensively should benefit more. There are no direct measures of industry road-use. But given the complementarity between roads and vehicles, vehicle-use provides an indirect measure of road-intensity.

The basic stylized fact of this paper is that changes in road growth are associated with larger changes in productivity growth in industries that are more vehicle intensive. First, the slowdown in productivity after 1973 appears larger in industries with higher vehicle shares. Second, when road growth rises, productivity growth tends to rise relative to the average in vehicle-intensive industries and fall in non-vehicle-intensive industries. Thus, the data strongly support the notion that industries with a lot of vehicles benefited disproportionately from road-building.

This finding suggests that the aggregate correlation between productivity and infrastructure reflects

1 Aschauer $(1989,1990)$ documents the correlation for aggregate U.S. data. Other studies using aggregate, regional, or industry data for the United States and reporting a large productive role for public capital include Morrison and Schwartz (1996), Kocherlakota and Yi (1995), Nadiri and Mamuneas (1994), and Munnell (1990). Studies using cross-country data include Berndt and Hansson (1992) and Ford and Poret (1991). Sceptics include Holtz-Eakin (1994a), Hulten and Schwab (1991), and Aaron (1991). Gramlich (1994) surveys the infrastructure literature, with additional references. 
causation from changes in the road stock to changes in productivity. For example, suppose roads do not contribute to productivity at the margin, but are endogenous: as aggregate productivity (and hence income) rises, the government chooses to build more roads. One would not then expect any particular relationship between an industry's vehicle-intensity and its relative productivity performance when road growth changes. Alternatively, suppose the correlation is spurious, reflecting a common trend slowdown in the early 1970s. There is no reason to expect a larger change in trend for industries that use a lot of vehicles.

Construction of the interstate highway system peaked in the late 1950s and early 1960s, and was largely completed by 1973 . The results suggest that this construction boom substantially boosted productivity. In particular, the point estimates imply that public investments had above-average rates of return, and contributed about 1 percentage point more to productivity growth before 1973 than after. Hence, public investment can explain a substantial share of the 1.3 percentage-point slowdown in productivity growth.

These results raise an important policy question: Does public investment offer a continuing, but neglected, route to prosperity? That is, by building roads, can we return to a path of renewed high productivity growth? The industry data do not support this conclusion: at the margin, we cannot reject that roads now offer a normal (or even zero) rate of return. Thus, the data seem most consistent with a story in which the massive road-building of the 1950s and 1960s offered a one-time boost to the level of productivity, rather than a path to continuing rapid growth in productivity.

This conclusion-that roads were exceptionally productive before 1973 but are not exceptionally productive at the margin-is consistent with simple network arguments. ${ }^{2}$ In particular, building an interstate network might be very productive; building a second network may not. The conclusion is also consistent with cost-benefit studies. The Congressional Budget Office (1991), for example, surveys these studies and reports an estimated average real return to new urban highway construction of 10 to 20 percent.

Finally, I explore the empirical importance of congestion. The empirical literature cited in Footnote 1 generally ignores congestion, and assumes that public capital is a pure non-rival public good. As a proxy for congestion, I use a measure of aggregate road use: total miles driven by trucks and autos. Figure 1

${ }^{2}$ Hulten (1994) discusses the network nature of infrastructure at length. 
shows that miles-driven continued to grow steadily after 1973 (though at a slower, and more variable, rate than before 1973), so that the average utilization of roads (e.g., miles driven per unit of the road stock) also rose steadily. At an aggregate level, miles-driven perhaps better measures total road services rather than congestion, which reduces road services. For an individual producer, however, total miles-driven largely reflects road use by other producers, and hence should reduce road services.

Congestion does not appear empirically important before 1973, but becomes empirically important thereafter. These results make intuitive sense. When the interstate highway system was first built, adding an additional car to the system may not affect the services available to any other user. As the system becomes more congested, adding more cars (and hence increasing total miles driven) reduces the services available to anyone else. Hence, congestion is inherently likely to be a non-linear process. The results suggest that congestion only became important after the interstate system was completed.

Section I develops formally the growth-accounting implications of the idea that vehicle-intensive industries use roads intensively. Section II describes the data, and discusses several econometric issues. Section III presents results. Section IV concludes.

\section{Method}

The first subsection considers the production decisions of firms, and formalizes the notion that industries that have a lot of vehicles use roads relatively intensively. The resulting estimating equation implies that when road services change, productivity should change by more in industries that are more vehicle intensive. The second subsection discusses how to model the services of roads, taking account of the network nature of the road stock and the potential importance of congestion.

\section{i. Growth accounting with public capital}

For each industry, suppose the production of value-added output $Y_{i}$ depends on inputs of non-vehicle capital $K_{i}$, labor $L_{i}$, and transport services that are produced within the sector $T_{i}$. Output also depends on the Hicks-Neutral state of technology $U_{i}$. Transport services depend upon the flow of services provided by the aggregate stock of government roads $G$ as well as the stock of vehicles in the sector $V_{i}$. Hence, omitting 
time subscripts for simplicity, each sectoral production function takes the form ${ }^{3}$

$$
Y_{i}=U_{i} F^{i}\left(K_{i}, L_{i}, T\left(V_{i}, G\right)\right) .
$$

Note that the production function (1) treats purchased and produced transport differently. Value added nets out the contribution of intermediate goods to production. So if, for example, a sector purchases trucking services, this represents value added in the trucking sector, not in the purchasing sector.

Suppose each firm is perfectly competitive and has constant returns to scale to private factors, which it can adjust instantaneously. Let $F_{J}$ represents the derivative of the production function $F$ with respect to input $J$. Cost-minimization then implies that the elasticity of output with respect to $J, F J / F$, equals that input's share in revenue, $s_{J i}$. The shares to private inputs sum to one, so there are no economic profits. Although we cannot directly observe the elasticity of output with respect to road services, we can expresse it relative to the elasticity with respect to vehicles, given by the share $s_{V i}$ :

$$
\frac{F_{G} G}{F}=\left(\frac{F_{G} G}{F_{V} V}\right) \cdot\left(\frac{F_{V} V}{F}\right) \equiv \phi_{i} s_{v i} .
$$

The parameter $\phi_{\mathrm{i}}$ equals the relative output elasticities of roads and vehicles, and is the key parameter linking observed vehicle-intensities to unobserved road use. We expect that $\phi_{\mathrm{i}}$ is positive, which captures the notion that vehicle-intensive sectors are also relatively road-intensive. As long as $\phi_{\mathrm{i}}$ is positive (even if not constant over time and industries), the estimating equation below holds at least approximately.

However, further assumptions on technology greatly simplify the formal derivation, and aid in interpreting the results. By the separability assumption in (1), $\phi_{\mathrm{i}}$ equals the ratio of the elasticities with respect to $G$ and $V$ in producing transport:

$$
\phi_{i}=\frac{T_{G} G}{T_{V} V}
$$

Now suppose all sectors have the same Cobb-Douglas transport aggregate $T$, so $\phi_{\mathrm{i}}=\phi$. The rest of the production function remains completely general, so the road elasticity can change over time as long as it remains proportional to the vehicle-share. This Cobb-Douglas assumption on $T$ provides a first-order

${ }^{3}$ The appendix considers the case in which industry-specific road stocks differ from the aggregate road stock, arising from differences in the regional distribution of production across industries. Footnote 7 briefly discusses the appropriateness of the assumption that a value-added production function exists. 
approximation to the true production function, and greatly simplifies the problem. It is worth noting, however, that for making inferences about the marginal productivity of roads, the second-order effects may be crucial. We can approximate a more general functional form by allowing the coefficient $\phi$ to change over time. ${ }^{4}$

Solow's productivity residual, $d p_{i}$, measures the growth in the productivity of private inputs in production. Let $d j$ represent the growth rate of input $J, d J / J$. Taking the total (logarithmic) differential of the production function (1), substituting input shares for output elasticities, and rearranging, we find:

$$
\begin{aligned}
d p_{i} & \equiv d y_{i}-s_{K i} \cdot d k_{i}-s_{L i} \cdot d l_{i}-s_{V i} \cdot d v_{i} \\
& =\phi \cdot\left(s_{V i} \cdot d g\right)+d u_{i} .
\end{aligned}
$$

Observed productivity growth depends on technology shocks $d u_{i}$ plus the contribution of governmentprovided roads. The services of these roads enter as an external effect related to vehicle use.

Aggregate productivity shocks, $d \bar{p}$, equal a weighted average of sectoral shocks:

$$
\overline{d p}=\sum_{i} w_{i} d p_{i}
$$

where the sectoral weights $w_{i}$ are the shares of nominal value added in aggregate value added..$^{5}$ Hence,

$$
\overline{d p}=\phi \cdot \bar{s}_{V} d g+\overline{d u} .
$$

Public investment, and hence the growth in the services of the road stock $d g$, may depend on the growth in output, which in turn depends on the growth in productivity $d \bar{u}$. In this case, ordinary-leastsquares estimation of the growth-accounting equation (6) suffers from simultaneity bias.

If public investment depends on aggregate income and hence productivity, ${ }^{6}$ then sectoral productivity shocks affect road growth by affecting the aggregate shock. Given that covariance is a linear operator,

4 Using a CES production function, for example, considerably complicates the theoretical and econometric problem. First, aggregation is difficult unless all producers are identical. Second, road growth varies relatively little after 1973 (the mean is 1 percent; the standard deviation 0.3 percent), so the U.S. data provide little variation to pin down complicated parameterizations. Allowing the coefficient to change approximates this complicated effect in a simple way.

5 See, for example, Jorgenson, Gollop, and Fraumeni (1987, p66).

${ }^{6}$ As a referee pointed out, this may not be the right model if industries are not distributed evenly across regions. The appendix considers this issue in detail. 
equation (5) then implies that the covariance between $d \bar{u}$ and $d g$ just equals the weighted-average of the covariance between sectoral shocks $d u_{i}$ and government capital $d g$. Thus, if the aggregate regression suffers from endogeneity bias, so do the sectoral regressions (4).

Now consider the following regression decomposition:

$$
d u_{i}=\beta_{i} \cdot \overline{d u}+\varepsilon_{i}
$$

The residuals $\varepsilon_{\mathrm{i}}$ from equation (7) are, by construction, orthogonal to the aggregate productivity shocks, and hence to the growth rate of government capital. The fitted values $\beta_{i} \cdot \overline{d u}$ measure the conditional expectation of the technology shock in sector $\mathrm{i}$, given the aggregate productivity shock. The average "cyclicality parameter" $\beta_{i}$ equals one: if there is an aggregate productivity shock of, say, 1 percent, then a typical sector has a productivity shock of 1 percent.

Substituting equations (6) and (7) into equation (4) gives the following estimating equation:

$$
\begin{aligned}
d p_{i} & =\phi \cdot s_{V i} \cdot d g+\beta_{i} \cdot \overline{d u}+\varepsilon_{i} \\
& =\phi \cdot s_{V i} \cdot d g+\beta_{i}\left[\overline{d p}-\phi \cdot \bar{s}_{V} d g\right]+\varepsilon_{i} \\
& =\phi \cdot\left(s_{V i}-\bar{s}_{V}\right) d g+\beta_{i} \overline{d p}+\varepsilon_{i}
\end{aligned}
$$

This non-linear regression equation, which I estimate in Section III, has the key attribute that the disturbance term is orthogonal to $d g$. Intuitively, the problem of endogeneity arises from an omitted variable, $d \bar{u}$; by combining aggregate and disaggregate data, we can control for this omitted variable.

So far, I have suppressed constant terms for simplicity. Suppose $d u_{i}=c_{i}+d z_{i}$, with $\beta_{i}$ defined by $d z_{i}=\beta_{i} \overline{d z}+\varepsilon_{i}$. Defining $\bar{c}$ as the average constant, and $\tilde{c}_{i}=c_{i}-\beta_{i} \bar{c}$, the estimating equation (8) becomes:

$$
d p_{i}=\tilde{c}_{i}+\phi \cdot\left(s_{V i}-\beta_{i} \bar{s}_{V}\right) d g+\beta_{i} \overline{d p}+\varepsilon_{i}
$$

For an intuitive interpretation, suppose all industries are equally cyclical, so the $\beta_{i}$ all equal one, and that any trends are common. Then rearranging equation (9), we find:

$$
d p_{i}-\overline{d p}=\phi \cdot\left[s_{V i}-\bar{s}_{V}\right] d g+\varepsilon_{i} .
$$

If roads are productive, then positive road growth $d g$ tends to makes the idiosyncratic component of sectoral productivity growth $\left(d p_{i}-\overline{d p}\right)$ positive in industries with above-average vehicle intensities, and below-average in industries with below-average vehicle intensities. In other words, changes in road growth should be 
associated with larger changes in productivity growth in vehicle-intensive industries.

If roads are not productive, then changes in road growth should not imply any particular relationship between vehicle-intensity and relative productivity performance. Similarly, if the aggregate correlation between productivity and public capital reflects common trends (e.g., shifts in the constant terms), it is unlikely that changes in trend are systematically larger for industries that have a lot of vehicles.

Clearly, the formal derivation above makes several simplifying assumptions that may not hold. Nevertheless, as long as roads have a larger productive effect in sectors that are vehicle intensive, the basic method should be fairly robust to misspecification. Misspecifications-arising from increasing returns, aggregation effects, factor-biased technological change, or other sources-only matter to the extent they are systematically correlated with vehicle-intensities. There is little reason to expect such a correlation. Moreover, any resulting bias (which could be either positive or negative) is likely to be small relative to the direct productive effect of roads in sectors that are vehicle-intensive. Misspecification does add an additional source of idiosyncratic variance to relative productivity performance, raising standard errors. ${ }^{7}$

\section{ii. Modeling road services and congestion}

Empirically, how should one model the services of roads? The empirical literature cited in Footnote 1 generally assumes that the services of public capital are a pure, non-rival public good, with services proportional to the stock of capital. Two considerations-the network nature of the road system, and

${ }^{7}$ Increasing returns, for example, is probably not a major concern, since the typical sector has approximately constant returns, and the correlation between the growth in roads and aggregate inputs is -0.04. However, Basu and Fernald (1997) find that because of industry heterogeneity, aggregation affects the cyclical properties of aggregate productivity, and has a larger effect on estimates with value added than gross output. The Basu-Fernald aggregation effects are virtually uncorrelated with road growth, and using gross output give results that are virtually identical to the value-added results reported in Section III. Hence, abstracting from aggregation and the non-existence of a value-added production function is probably unimportant here.

As an additional check for misspecification, in the empirical work I added proxies for energybiased technical change and variable capacity utilization. In particular, I added an oil-price dummy to the regressions (with a different effect by industry), which might matter if technical progress were more energy-biased in vehicle-intensive sectors. Results changed little. I also added the change in hours per worker as a proxy for unobserved changes in labor and capital utilization (see Basu and Kimball (1997)). Again, results changed little. 
congestion-have implications for modeling road services, and interpreting the results. ${ }^{8}$

First, the road system forms a spatially interconnected network. For a network, the conventional perpetual inventory method of measuring capital stocks is generally not appropriate. In particular, the internal composition of the stock matters, since the marginal productivity of any one link depends on the capacity and configuration of all the links in the network. Using measures of the total stock thus may allow us to estimate the average marginal product of roads in the past, but these estimates may not be appropriate for considering the marginal product of additional roads today.

Moreover, as Hulten (1994) notes: "Once the basic links of a network are established, the opportunities for complementary investments diminish and the construction of new capacity gradually comes to substitute for existing capacity." In other words, building the interstate network may have been very productive, but building a second interstate system may not be. Allowing the coefficient on roads to change over time provides one simple way to capture this idea.

Second, roads are subject to congestion. Congestion may not be important when a network is first built, but it becomes important as more people use the system. For example, adding a second car to an interstate highway does not reduce the services received by the first car. At rush hour in most cities, however, additional cars slow traffic, and reduce the services received by existing drivers.

A simple way to model average congestion is to express road services as

$$
G=\frac{R}{C^{k}},
$$

where $R$ is the road stock and $C$ is some measure of road use and hence congestion. Barro and Sala-i-Martin (1995) suggest that in modeling long-run economic growth, aggregate output or private capital might proxy for congestion $C$. Mankiw (1992) models $C$ as the aggregate vehicle stock. In the short run, however, capital and vehicle-stock proxies do not account for variations in the utilization of these stocks, while the output-proxy has the disadvantage that the regression already includes aggregate productivity (closely related to aggregate output). In my empirical results, I instead model congestion $C$ as a function of the total miles driven by trucks, automobiles, and other motor vehicles.

${ }^{8}$ Much of the discussion below follows Hulten (1994), who discusses the implications of networks and congestion in terms of simple models of optimal growth, and discusses the implications of these issues for econometric modeling. 
The parameter $k$ measures how quickly the road services received by any individual producer fall as aggregate miles-driven rise. If roads are a pure public good, $k$ equals 0 . Barro and Sala-i-Martin and Mankiw suggest that a particularly attractive specification is if $k$ equals 1 , so that $G=R / C$. With this specification, any individual producer appears to have increasing returns to private and public inputs, because he or she takes road-use by others as given. At an economy-wide level, however, there are constant returns to scale if miles driven increase proportionally with other inputs.

With congestion, the estimating equation becomes:

$$
d p_{i}=\tilde{c}_{i}+\phi \cdot\left(s_{V i}-\beta_{i} \bar{s}_{V}\right) d r-\kappa \cdot\left(s_{V i}-\beta_{i} \bar{s}_{V}\right) d c+\beta_{i} \overline{d p}+\varepsilon_{i}
$$

where $\kappa$ equals $k \phi$, and $d r$ and $d c$ are the growth rates of roads and congestion. In other words, an increase in roads disproportionately helps vehicle-intensive industries, while an increase in congestion disproportionately harms these industries.

A convenient interpretation of $\phi$ is in terms of the implied annual rate of return: the value of the increased annual flow of goods and services coming from an extra dollar of roads. The rate of return equals the sum of the real value of the marginal products across sectors. Let $Y$ be aggregate value added, and $P$ be the aggregate price deflator. It can be shown that: ${ }^{9}$

$$
\sum_{i}\left(\frac{P_{i}}{P}\right) \frac{\partial F^{i}}{\partial R}=\sum_{i}\left(\frac{P_{i}}{P}\right) F_{G i}\left(\frac{\partial G}{\partial R}\right)=\phi \cdot \overline{s_{V}} \cdot\left(\frac{Y}{G}\right) .
$$

The intuition is straightforward. In a Cobb-Douglas production function, the rate of return equals the factor's output elasticity (i.e., its share) multiplied by the ratio of output to the input. Here, the product $\phi \cdot \bar{s}_{V}$ is the aggregate elasticity of roads. In 1989 , the average vehicle-share was 1.5 percent (close to the average of 1.6 percent for the entire period from 1953 to 1989 , shown in Table 1). The ratio of aggregate valueadded in the private business economy to the value of the road stock was about 4 in 1989 , so for any estimate of $\phi$, we obtain an implied rate of return by multiplying by $(0.015 \cdot 4)$, or about 6 percent.

\footnotetext{
${ }^{9}$ This calculation assumes that miles driven and the vehicle share are not affected by the policy change in the stock of roads. Empirically, in annual data the elasticity of miles driven with respect to roads appears small. Regressing the log of miles driven on log GDP, log fuel prices, and the log of the road stock gives a road elasticity of 0.04 . Estimated in differences, this elasticity is 0.15 .
} 


\section{Data and Econometric Issues}

I use unpublished data provided by Dale Jorgenson and Barbara Fraumeni on inputs and outputs for 29 sectors of the U.S. economy, for the years 1953-1989. These sectors span the private business economy, excluding agriculture and mining. These data seek to provide measures of output and inputs that are, to the extent possible, consistent with the economic theory of production, and allow Jorgenson to allocate U.S. productivity growth to its sources at the level of individual industries. ${ }^{10}$

The data include gross output, and inputs of capital, labor, energy, and materials. Inputs are adjusted for changes in the composition of the labor force and the capital stock. For example, labor input weights hours-worked by different types of workers by estimates of relative wages, and capital input weights capital-stock by different types of capital by estimates of relative rental rates.

I estimate sectoral productivity growth from equation (4) as a Tornquist or translog index, replacing differentials with log-differences. Let $\bar{k}$ equal a translog index of vehicles and other capital. Then the Tornquist index of value-added productivity growth $\Delta p_{i t}$ is

$$
\Delta p_{i t}=\left[\frac{1}{1-s_{M i}}\right]\left[\Delta q_{t}-s_{\tilde{K i}} \Delta \tilde{k}_{i t}-s_{L i} \Delta l_{i t}-s_{M i} \Delta m_{i t}\right]
$$

All quantity variables are logs of their uppercase counterparts, and $q_{t}$ is the log of gross output. The weights - for example, $s_{M i}$-are the average input shares in periods $t$ and $t-1$. Dividing by the share of value added in gross output $\left(1-s_{M i}\right)$ converts this from productivity growth in terms of gross output to productivity growth in terms of a Divisia index of value added. ${ }^{11}$

I calculate the vehicle-share following Hall and Jorgenson (1967) and Hall (1990), multiplying the current value of the stock of vehicles by an estimate of the user cost of capital. I estimate the user cost as:

10 I exclude data on the government sector because complete input data are not available; I exclude agriculture and mining because many of their vehicles are not used on public roads. These data are available from 1947 onwards; a longer sample period is preferable econometrically, but the quality of the early data is also lower than that of the later data. In any case, the main conclusions appear to be relatively robust to using an earlier or later starting date. For a complete description of the data, see Jorgenson, Gollop, and Fraumeni (1987).

11 See Jorgenson, Gollop, and Fraumeni (1987), p52, or Basu and Fernald (1995, 1997). 


$$
r_{s}=\left(\rho+\delta_{s}\right) \frac{\left(1-I T C_{s}-\tau d_{s}\right)}{(1-\tau)}, \quad s=\text { trucks, autos }
$$

$\rho$ is the required rate of return on capital, and $\delta_{s}$ is the depreciation rate for this asset. ITC is the investment tax credit, $\tau$ is the corporate tax rate, and $d$ is the present value of depreciation allowances. Following Hall (1990), I assume that the required return $\rho$ equals the dividend yield on the S\&P 500. Following Jorgenson and Yun (1990), I take the depreciation rate to be 25.37 percent for trucks and 33.33 percent for autos. Dale Jorgenson provided unpublished data on $\tau, \mathrm{ITC}_{s}$, and $\mathrm{d}_{\mathrm{s}}$. Jorgenson also provided perpetual inventory estimates of the current value of the stock of trucks and autos by industry.

Using data on gross public investment in roads (from the U.S. Commerce Department 1995), I follow Boskin, Robinson, and Huber (1989) and assume that roads depreciate geometrically at a rate of 1.98 percent per year. Using the perpetual-inventory method, I then estimate the constant-dollar value of the stock of roads for each year. I assume that road input in a given year depends on the stock of roads at the beginning of the year. The resulting stock estimates generally exceed the Bureau of Economic Analysis estimates of the net road stock by a small amount, though the different estimates have a negligible effect on the estimates reported in Section III.

To measure congestion, I use a measure of overall road use: the total miles driven by trucks and autos in each year. These data are from the Federal Highway Administration (various years).

Note that it will generally be the case that the constructed regression disturbances are correlated across equations. It is easy to show that

$$
\operatorname{Cov}\left(\varepsilon_{i t}, \varepsilon_{j t}\right)=\operatorname{Cov}\left(d u_{i t}, d u_{j t}\right)-\beta_{i} \beta_{j} \operatorname{Var}(\overline{d u})
$$

This is in general non-zero. Hence, if we estimate the regressions in equations (9) or (10) as a system, there are efficiency gains to taking account of the cross-equation correlations among the disturbances.

On both economic and econometric grounds, I aggregate the 29 industries in various ways to reduce the number of equations I estimate. Econometrically, equation (16) implies that the regression disturbances are generally correlated across equations. Estimating the model as a system of seemingly unrelated regressions allows for these contemporaneous correlations. A necessary condition for SUR estimation is that 
the number of observations exceed the number of equations, or else the estimated covariance matrix is always singular. With 37 years of data, this necessary condition for non-singularity is satisfied, but the resulting estimates potentially suffer from small sample problems. In essence, the covariance matrix is poorly estimated, but feasible GLS nevertheless inverts it in estimating coefficients and standard errors. The resulting estimates are not reliable.

In addition, there is an economic rationale for combining industries. Investments in roads have a clear regional or geographical component. The less aggregated are the industries we choose, the more regional each industry is likely to be. As discussed in the appendix, the correct measure of an industry's road stock should then be some appropriately-weighted measure of regional stocks. This misspecification potentially leads to bias if industries are not distributed equally across regions, and if there are systematic differences in growth rates of roads across regions. This bias also depends heavily on the deviation of vehicle-intensities from the average. The appendix also presents some simple simulations, using regional data on public capital growth from 1971 through 1987, suggesting that the bias can be sizeable.

My main industry grouping seeks to minimize the bias by grouping industries to ensure that vehicleintensities are sufficiently different from the average, and that production is relatively evenly distributed across regions. The appendix describes the nine industry aggregates that result. Note also that having vehicle-intensities that differ substantially from the average increases the variation of the right-hand-side regressor in equations (9) and (10), and hence improves the precision of estimates of $\phi$.

For comparability, and to ensure that the results are not driven by my choice of aggregates, I also present results for three functional groupings. First, I use (approximate) one-digit SIC codes, comprising non-durables manufacturing, durables manufacturing, construction, transportation, communications, public utilities, trade, finance-insurance-real estate, and services. Second, I use the 21 manufacturing industries. Third, I use the eight non-manufacturing, non-farming, and non-mining industries.

\section{Results}

Table 1 lists the 29 industries that constitute the private business economy (excluding mining and agriculture) in the Jorgenson-Fraumeni data. Column (1) shows average annual value-added productivity 
growth from 1953 to 1989 ; column (4) shows the change after $1973 .{ }^{12}$ The industries are listed by the average share of value added going to vehicles, shown in Column (5). For the private economy as a whole, the next-to-last line shows that productivity growth was 1.6 percent per year from 1953 to 1989 , then fell to 0.3 percent from 1973 to 1989 . The aggregate vehicle share averaged 1.6 percent.

The growth in roads averaged 4 percent per year before 1973 , but only 1 percent after that. Suppose roads are productive, and that this slowdown in road growth explains a substantial portion of the slowdown in productivity growth. Since slower road growth should primarily affect sectors that use a lot of roads, these sectors should have had a greater slowdown in productivity growth.

Figure 2 graphs the change in sectoral productivity growth after 1973 versus average sectoral vehicle-intensity, using the data in columns (3) and (5) of Table 1, excluding the obvious productivity outlier of petroleum products. ${ }^{13}$ The estimated slope (shown in the figure) is -0.63 , with a t-statistic of 2.30 . Thus, the simple cross-sectional evidence in the figure is consistent with the notion that sectors with greater vehicleintensities tended to experience larger productivity slowdowns after 1973.

The negative correlation (though not always its statistical significance) is relatively robust to the presence of outliers. For example, in Figure 2, which excludes petroleum products, the correlation was -0.41 ; including petroleum products reduces the correlation to -0.29 (significant at about the 85 percent level). Excluding the two vehicle-share outliers (transportation and gas utilities) reduces the correlation further, to -0.24 (significant at about the 80 percent level). However, excluding all industries with aboveaverage vehicle intensities restores the correlation to -0.43 , significant at the 95 percent level.

Although the correlation is always negative, the influence of outliers suggests that changes in road

121973 is the traditional dating of the productivity slowdown, though some date it earlier and some later. Later, for convenience I allow coefficients to change in 1973, as well; it does not appear that using other proposed break dates substantively changes the picture or the coefficient estimates.

13 The extraordinary productivity performance of petroleum and coal products reflects enormous annual variability of annual value-added productivity growth, which has a standard deviation of 36 percent per year. Several years of abnormal positive productivity performance in the 1980s substantially increase the post-1973 mean. The enormous standard deviation, in turn, largely reflects the very high materials share, which averages 90 percent of gross output; value-added is only 10 percent of gross output. Hence, small productivity changes in gross output translate into enormous productivity changes in value added. Fortunately, none of the substantive results below are sensitive to including, or not including, petroleum products-or to doing the estimation with value-added rather than gross output. 
stocks are not the only important feature of the post-1973 environment. In fact, the dominant feature of Figure 2 is the wide dispersion of productivity performance after 1973. As documented in the final line of Table 1, the standard deviation of productivity growth across industries increased from 1.3 percent before 1973 (column 2) to nearly 3 percent after 1973 (column 3). ${ }^{14}$ (Even excluding petroleum and coal products, the standard deviation nearly doubles) Some sectors have done extraordinarily well, such as petroleum products, industrial machinery, and textiles. Other sectors have done extraordinarily poorly, such as utilities, chemicals, and printing.

Hence, though slower public investment may explain some of the slowdown in productivity growth in the economy, it does not explain why the variance of productivity growth across sectors increased after 1973. Aschauer (1989) and others have suggested that the decline in public investment is the main cause of the change in productivity performance after 1973; by contrast, the cross-industry variance of post-1973 performance evident in Figure 2 indicates that while public investment may explain some of the mean slowdown, it cannot explain all of the changes in productivity moments. This conclusion matches intuition that a wide range of influences-such as environmental regulation, oil price shocks, and microcomputers-affected the economy after 1973, with different effects on different industries.

The rest of this section explores the productivity of roads more formally, using the estimating equation from Section I. This equation uses within-industry variation to explore how variations in road growth is associated with variations in the relative productivity performance of different industries. Table 2 presents the basic results for four sets of industries. The first set, discussed in the Appendix, comprises nine "aggregate" industries, where the aggregates are chosen to minimize any bias coming from differences in the relevant measure of roads across industries. The second set are one-digit SIC industries. The third set are the 21 manufacturing industries, and the fourth set are the 7 non-manufacturing industries. The odd columns contain the basic regressions, which assume that the parameter $\phi$ is constant over time. The even columns allow the coefficient on roads to change after 1973; the change in the coefficient is shown in the second row of the table.

14 This increased variability shows up in the underlying annual data, as well. The annual standard deviation in productivity growth rates across sectors was 4 to 6 percent before 1973 , and 8 to 15 percent from 1973 to 1985. 
Considering the odd columns first, the parameter $\phi$ is always large and significant. That is, variations in road growth are associated with variations in the relative productivity performance of different industries. For example, in both columns (1) and (3), $\phi$ is about 22, with a t-statistic of around 6.5 .

This finding that $\phi$ is large and significant is robust to industry groupings. The estimated coefficient is largest in manufacturing (column 5), and smallest in non-manufacturing. Note that this does not imply that roads contributed more to productivity performance in manufacturing than non-manufacturing industries. Rather, it implies the opposite, since manufacturing industries generally have a low vehicle intensity. Hence, when road growth increased in the 1950s and 1960s, productivity growth in manufacturing declined relative to the average.

One concern, raised while discussing Figure 2, is that results may be sensitive to outliers. Therefore, the robustness of results to using four different industry groupings is reassuring. Note that the estimating equation explicitly attempts to account for reverse causation from aggregate productivity shocks to roads; the robustness to different groupings suggests that results are probably not driven by some other, unaccounted-for "endogeneity" concern. For example, government roadbuilding might respond primarily to shocks to high-vehicle industries; the large estimate for manufacturing industries (which tend to have few vehicles) suggest that this is not a problem. Alternatively, perhaps roadbuilding responds especially to manufacturing shocks, since manufacturing has a high profile; however, the coefficient remains statistically significant in non-manufacturing. (Moreover, since manufacturing has few vehicles, endogeneity from manfacturing productivity shocks to roads would biased the coefficient down, whereas in the data the coefficient is very large and positive.

An additional concern is that results might be driven by one or two industries. Note that the first two groupings (especially the aggregated grouping) tend to minimize these individual outliers by combining industries. Nevertheless, I explored the sensitivity of results to including, or not including, various industries. For the baseline aggregated grouping, I dropped each of the nine groups in turn, to ensure that no individual grouping was driving the results. The estimate of $\phi$ always remains large and statistically significant. For example, adding or excluding petroleum products and tobacco-two industries often considered suspect-has little effect on the estimate of $\phi$ in the aggregated industry grouping, or in 
manufacturing. Dropping gas utilities and transportation (two outliers from Figure 2) has little effect on the aggregated, one-digit, or non-manufacturing results.

The coefficient $\phi$ has several economic interpretations. First, we can convert $\phi$ to an implied CobbDouglas coefficient by multiplying by the average vehicle-share, which is 1.6 percent. Hence, $\phi$ equal to 22 corresponds to a Cobb-Douglas coefficient on roads of about 0.35 . This is large, but in the ballpark of other estimates in this literature, obtained with very different identifying assumptions. (For example, Aschauer 1989, uses total aggregate public capital and reports a coefficient of 0.3 ; redoing his simple aggregate Cobb-Douglas regression using roads alone gives an almost identical coefficient).

Second, we can ask how much of a productivity slowdown this estimate implies. Average road growth was 4 percent per year before 1973, but only 1 percent after. The growth-accounting equation 5 implies that roads contribute $\phi \cdot \bar{s}_{V} d g$ to growth; an estimate of $\phi$ of 22 implies that roads contribute about 1.4 percent per year before 1973 , and about 0.4 percent after. This 1 percent reduction in the contribution of roads to growth compares with a total slowdown in productivity of 1.3 percent, shown in the next-to-last row of Table 1, column (4). Hence, the estimate implies that while roads cannot explain the sizeable dispersion in industry performance after 1973 , they may be able to explain a substantial fraction of the slowdown in mean productivity growth. ${ }^{15}$

Third, we can ask how the estimate relates to the slope of Figure 2, which relates the productivity slowdown to vehicle intensity. Since the growth in roads fell by 3 percentage points after 1973, the slope should be $-\phi(0.03)$. $\phi$ equal to 22 implies a slope of -0.66 , close to the actual slope of -0.63 . Thus, the estimates in Table 1 are consistent with the visual data in Figure 2.

Fourth, we can convert the estimate into a rate of return. As discussed in Section I.ii, suppose the estimates reflect the current marginal relationships. Then the rate of return is $\phi \cdot \bar{s}_{V}(Y / R)$, or $\phi \bullet 6$ percent. The estimate in column (1), for example, implies a rate of return of more than 130 percent per year-building an extra dollar's worth of roads adds more than a dollar to GDP every year. To reduce the

15 In principle, roads could "account for" more than 100 percent of the slowdown, if other factors, such as computers, raised productivity after 1973. 
rate of return to a more reasonable level of perhaps one-tenth as large ${ }^{16}$ requires a ten-fold reduction in the output-road ratio Y/R. Hence, at the current level of output, we would require 10 times as many roads, or nearly $\$ 12$ trillion.

Such high rates of return seem implausible at the margin; equivalently, it seems implausible that the optimal road stock is ten times its current level. A much more plausible interpretation, consistent with the suggestions of Hulten (1994), is that building one network may have a very high rate of return; but building a second network may have a very low marginal return. For example, the interstate highway system may have been extraordinarily productive. But building a second interstate highway system (let alone nine more highway systems!) may not have a large effect at the margin.

To explore this possibility, the even columns of Table 2 allow the coefficient to change after 1973, roughly when the interstate highway system was completed. $\phi_{73}$ represents the change in the coefficient, so the marginal coefficient equals the sum of the two parameters. In all cases, the point estimate is negative, suggesting that the marginal contribution of building roads is lower than the average contribution. For the aggregated industries and for non-manufacturing, the point estimates imply that the marginal effect of building additional roads is negative. More accurately, for all groups, we can reject that roads are unproductive in the pre-1973 period (in the first row); for all groups other than manufacturing, we cannot reject that the marginal productivity of roads to GDP is zero.

Since the standard errors on the post- 73 change in coefficient are very large, the results are suggestive rather than definitive. For example, the point estimate on the marginal effect of roads-the sum of $\phi$ and $\phi_{73}$-has an enormous standard error, generally on the order of 15 . Even where $\phi_{73}$ is significant, as in column (2), the results are not necessarily robust to changes in specification (see Table 3 below, for example). Econometrically, the problem results from the lack of variability in road growth in the post-1973 period; the standard deviation of road growth is 0.9 percent before 1973 , and 0.3 percent after. This lack of variation in the right-hand-side regressor reduces the information in the data, and increases standard

${ }^{16}$ For example, suppose the real interest rate is about 4 percent, and the depreciation rate of roads about 2 percent. Also suppose that the marginal excess burden of taxation is 2 (at the high end of current estimates, discussed, for example, by Jorgenson and Yun 1990 and Morrison and Schwartz 1996). Then an optimizing government would set the marginal return on roads equal to twice the Hall-Jorgenson cost-ofcapital of 6 percent. 
errors. Thus, while the data strongly reject the proposition that roads offered a normal return in the pre1973 period, the data do not speak strongly to the marginal effect of roads.

However, as discussed in Section I.ii, there are strong a priori reasons to expect that a network may offer large one-time benefits, but adding a second identical network will not. Also, there are strong grounds to be skeptical of enormous, unexploited marginal rates of return in excess of 100 percent. Thus, an appropriate interpretation of the post- 1973 results is that the data are consistent with these priors-there is no evidence that roads offer an abnormal return at the margin.

Given that the aggregated industry groupings are least likely to be subject to bias, I henceforth focus on that set of industries. Table 3 adds total miles driven as a proxy for congestion, and also explores the possibility that the congestion coefficient may change over time. For example, the interstate highway system by its very nature is a lumpy investment, and when first built, adding an additional car to the system may have had little effect on the services available to any other user. As the system becomes more congested, adding more cars (and hence more miles driven) reduces the services available to anyone else. Hence, congestion is inherently likely to be a non-linear process; the change in coefficient provides a very crude approximation to this nonlinearity.

The first two columns assume that congestion is a stable linear function of the total miles driven by all users. The coefficient $\kappa$, capturing the effect of congestion, is insignificant. Adding congestion has a relatively small effect on the road-coefficient $\phi$, although it does reduce the size and significance of $\phi_{73}$.

The rest of the columns allow the congestion coefficient to change after $1973 ; \kappa_{73}$ shows the change in the coefficient. In all cases, the pre-1973 coefficient is insignificant, and often the wrong sign to proxy for congestion; but the coefficient generally rises by a statistically significant (except in Column 4) amount after 1973. The estimates imply that after 1973, an increase in total miles-driven significantly reduces the services of roads to any individual producer.

Columns (4) and (5) allow the coefficient on both roads and miles driven to change after 1973 . The point estimate suggests that roads are less productive at the margin; but the standard error remains very large, so the estimate is extremely imprecise. The coefficient on congestion again rises 1973, though the t-statistic falls from 2.2 in Column (3) to 1.2 in Column (4); multicollinearity appears to be a problem with 
disentangling the post-1973 effects. Finally, the fifth column drops the two least significant coefficients from the fourth column, keeping the two "robust" coefficients: $\phi$ and $\kappa_{73}$. The estimate again implies that roads are highly productive, and that congestion is important after 1973.

To summarize the results of Tables 2 and 3, the data strongly reject the null hypothesis that roads did not, on average, affect relative industry productivity performance; before 1973, in particular, the data indicate that roads contributed substantially to productivity growth. However, the data do not reject the null hypothesis that roads offer a "normal" (or even zero) return at the margin. Finally, using total miles driven as a measure of congestion, the results suggest that congestion became important only after 1973, after the interstate system was completed. These results are consistent with simple stories of networks, such as those discussed by Hulten (1994).

Given these results, it seems reasonable to consider a specification in which the highway system was not subject to congestion before 1973; after 1973, when congestion became important, the services of roads take the form of equation (11), in which roads and miles-driven have coefficients that are equal in magnitude. The regressions in Table 3, for example, do not reject this specification (largely, of course, because the estimates of the marginal coefficient on roads are so imprecise). Econometrically, making this identifying assumption of coefficient-equality has the advantage that miles-driven vary much more than road-growth does. Hence, we can use the variation in miles-driven to help pin down the marginal effect. Note that this specification implies that if roads and road-use increase proportionately, there is no increase in the "services" of roads.

Table 4 shows these results. As before, roads appear strongly productive before 1973. After 1973, the productivity of roads is statistically-significantly smaller, and we cannot reject that roads have a normal (or even zero) return. As a final specification test, the second column adds a post-1973 dummy for each industry, allowing an industry-specific change in trend growth. This trend-break should capture other influences in the post-1973 period that may affect productivity. It will only matter if the industry-specific change in trend is correlated with vehicle-intensities; if the change in trend is common to all industries, for example, results will be unaffected. There is no reason to expect a correlation between the trend-shift and vehicle-intensity, so not surprisingly, the results are qualitatively unaffected. The standard error on $\phi_{\text {Pre-73 }}$ 
rises substantially, but the coefficient remains statistically significant. (In other specifications in Tables 2 and 3 , adding industry-specific post-73 dummies makes it more difficult to identify post-73 coefficient changes, given multicollinearity-the correlation between road growth and the post- 73 dummy is 0.85 , for example. However, none of the qualitative conclusions are affected.)

The specification in Table 4 has some a priori plausibility. Hence, though the data do not pin down the marginal parameter with precision, these results again provide further support for the interpretation above: roads had an above-normal return before 1973, but probably do not have an above-normal return today; moreover, congestion now reduces the productive services of roads.

\section{Conclusion}

Industry data from 1953 to 1989 strongly support the view that vehicle-intensive industries benefited disproportionately from road-building. First, the slowdown in productivity after 1973 appears larger in industries with higher vehicle shares. Second, when road growth rises, productivity growth tends to rise relative to the average in vehicle-intensive industries and fall in non-vehicle-intensive industries. These results suggest that the aggregate correlation between productivity and public capital primarily reflects causation from public capital to productivity, and that public investment may account for a substantial share of the slowdown in productivity growth after 1973.

However, the industry data do not support the view that roads offer an abnormal return at the margin, or that returning road growth to pre-1973 levels would raise productivity growth to pre-1973 levels. In essence, the evidence suggests that the massive road-building of the 1950s and 1960s-which largely reflected construction of the interstate highway network-offered a one-time increase in the level of productivity, rather than a continuing path to prosperity.

These findings shed light on other results in the recent empirical literature on infrastructure. Results vary widely, depending on dataset, sample period and specification. Aschauer (1989) estimates an aggregate Cobb-Douglas production function in levels, and finds that public capital appears abnormally productive. Aaron (1991) points out that Aschauer's results are not robust to estimating in first differences, suggesting that perhaps Aschauer's results reflect a misspecification of trend. However, the sensitivity to first- 
differencing largely reflects a dramatic increase in standard errors-the aggregate data do not have sufficient information to differentiate the two interpretations. The industry results in this paper suggest that Aschauer's simple aggregate regression appropriately captures the high productivity of public capital in the pre-1973 period.

Using regional data on public capital also increases data variation (thereby improving precision). Studies using these data, which are only available after 1970, tend to find little evidence that public capital has an important productive effect. Munnell (1990) uses state data, and finds that public capital appears highly productive. However, Holtz-Eakin (1994) overturns her results when he includes state-specific fixed effects: the point estimates are negative, though not significantly so. Since fixed effects seem preferable, he concludes that these data offer no evidence that public capital has a non-normal (or even non-zero) productive effect. Similarly, Hulten and Schwab (1991) use manufacturing gross-output data on census regions, and find no evidence that productivity grew faster in regions with rapid growth in public capital. The results in this paper suggest that the regional findings may reflect the sample period: regional data are only available for the period when I find no evidence that roads have an above-normal return.

More recently, Morrison and Schwartz (1996) use state manufacturing data from 1970 to 1987, and suggest that public capital may have a rate of return of 20 to 30 percent in the manufacturing sector alone. Since non-manufacturing (roughly 80 percent of the economy) benefits from public capital as well, these results suggest that public capital is far underprovided.

There are several interpretations of the differences between their results and mine. First, Morrison and Schwartz place few restrictions on how government capital enters the production function; government capital may provide indirect "externalities" that I miss, or perhaps make possible other Caballero-Lyons style externalities (though there is not much evidence for these externalities in gross-output data; see Basu and Fernald 1995). Since I explicitly focus on the direct effects, my results are likely to understate the returns to public capital if externalities are important. Second, however, Morrison and Schwartz do not control for endogeneity of public capital, other inputs, or even output (all of which are explanatory variables in their 
flexible cost function). ${ }^{17}$ Since states with high productivity shocks may tend to invest more in public capital, the Morrison and Schwartz results could reflect the endogeneity of public capital, and hence be (presumably) biased upwards. I explicitly account for the endogeneity of public capital, and hence may obtain more reliable results.

In any case, it remains unclear why Morrison and Schwartz get different results from other regional studies, who also have no controls for endogeneity. Morrison and Schwartz attribute the differences to using a flexible functional form, which allows a second-order approximation to the cost function; but the differences in results appear to be driven by the first-order effects, not the second-order effects.

Finally, my results have implications for interpreting the productivity slowdown. A common presumption is that pre-1970s levels of growth were normal. An alternative interpretation suggests that perhaps it was the immediate post-war decades that were unusual, with a "return to normal" after the early 1970s (e.g., Wolff 1996). My results support this interpretation: road-building accounts for a substantial share of the productivity slowdown by raising pre-1973 productivity growth, but cannot offer the same benefits at the margin.

Yet another interpretation of the productivity slowdown suggests that perhaps the slowdown reflects mismeasurement; Griliches (1994), for example, argues that an increasing proportion of the economy consists of sectors where output is poorly measured. Computers may also make quality-improvements and product-differentiation easier, and conventional statistics may miss these benefits. The results in this paper suggest that roads contributed much less to productivity after 1973 than before, and from a growthaccounting perspective, can explain a significant share of the productivity slowdown. These results thus point in the direction of a real slowdown.

However, it may be that "true" productivity growth (after accounting for mismeasurement) did not slow, since computer-driven technological innovations increased. The computer paradox (Solow: “We see computers everywhere except in the productivity statistics") may reflect the coincidence of the

17 They suggest that using lagged values as instruments, or using the Hall-Ramey instruments, has little effect on results other than raising standard errors. Given that public and private capital are highly autocorrelated, and given that the Hall-Ramey instruments have no explanatory power for capital, these attempts may not resolve the issue of endogeneity. 
microcomputer revolution with the reduced contribution of roads. In other words, even if we fully measured the substantial technological benefits of computers, productivity statistics might show no improvement. More generally, history may often display unusual influences-road networks, computers, mass-production techniques, steam engines-that affect productivity for decades. Under this interpretation, roads may have raised productivity before 1973, just as computers raise "true" (though perhaps unobserved) productivity today. 


\section{Appendix: The Bias from an Uneven Distribution of Industries}

If industries are not distributed evenly across space, then the aggregate road stock does not correctly measure industry-specific road input. Instead, the appropriate measure should probably be a weighted average of regional road growth rates, weighted by the importance of each region in the industry's production. This appendix considers the potential bias that results from incorrectly using the aggregate road stock.

Following the derivation in Section I, suppose that in each location, an industry can produce with the production technology from equation (1), and that the industry has the same vehicle share, $s_{V i}$, in all regions. Aggregating industry productivity over regions, we find:

$$
d p_{i}=\phi \cdot s_{V i} \cdot d g_{i}+d u_{i},
$$

where $d g_{i}$ is the growth in the industry-specific input of government roads. $d g_{i}$, in turn, is defined by:

$$
d g_{i}=\sum_{j} w_{i j} \cdot d g^{j},
$$

where $d g^{j}$ is the growth in roads in region $j$, and $w_{i j}$ is the share of industry $i$ 's production in region $j$.

We can rewrite equation (17) as

$$
d p_{i}=\phi \cdot s_{V i} \cdot d g+\phi \cdot s_{V i}\left(d g_{i}-d g\right)+d t_{i},
$$

where $d g$ is the growth in the national, or aggregate, road stock. Assuming that public capital is distributed in proportion to production, ${ }^{18}$ the national road stock $d g$ equals:

$$
d g=\sum_{j} w^{j} d g^{j}
$$

where $w^{j}$ is the share of national production in region $j$. Comparing (18) and (20), $\left(d g_{i}-d g\right)$ is zero if roads grow at the same rate in all regions, or if industries produce equally across regions, so that $w_{i j}$ equals $w^{j}$.

Aggregating over industries, aggregate productivity $d \bar{p}$ is:

$$
\overline{d p}=\phi \cdot \bar{s}_{V} \cdot d g+\phi \cdot\left[\sum_{i} w_{i} s_{V i}\left(d g_{i}-d g\right)\right]+\overline{d u} .
$$

Suppose, for simplicity, that the industry cyclicality parameters, $\beta_{i}$, equal unity for all $i$. We can then write the difference between industry and aggregate productivity as:

18 This assumption simplifies notation and interpretation. In practice, of course, government capital is aggregated using the distribution of that capital, not the distribution of production. If these distributions differ, then all studies using the aggregate stock of government capital are misspecified. This misspecification matters only if the difference between the two measures are correlated with the aggregate stock of government capital. 


$$
d p_{i}-\overline{d p}=\phi \cdot\left(s_{V i}-\bar{s}_{V}\right) \cdot d g+\phi \cdot\left[s_{V i}\left(d g_{i}-d g\right)-\sum_{i} w_{i} s_{V i}\left(d g_{i}-d g\right)\right]+\varepsilon_{i},
$$

where $\varepsilon_{i}$ is the idiosyncratic component of industry productivity growth. $\varepsilon_{i}$ may be correlated with the industry-specific $d g_{i}$, but as long as the industry is relatively small, $\varepsilon_{i}$ should be nearly uncorrelated with aggregate road growth.

Suppose we attempt to estimate the linear regression in equation (22), but omit the term in brackets. If the vehicle shares are constant over time, then the plim of the ratio of the estimated to true regression coefficient is:

$$
\operatorname{plim} \frac{\phi_{i}}{\phi}=1+\left(\frac{1}{s_{V i}-\bar{s}_{V}}\right)\left[s_{V i} \cdot \frac{\operatorname{Cov}\left(d g, d g_{i}-d g\right)}{\operatorname{Var}(d g)}-\frac{\operatorname{Cov}\left(d g, \sum_{k} w_{k} s_{V k}\left(d g_{k}-d g\right)\right)}{\operatorname{Var}(d g)}\right]
$$

Suppose industry weights are (relatively) constant over time. Then this plim ratio equals:

$$
\operatorname{plim} \frac{\phi_{i}}{\phi}=1+\left(\frac{1}{s_{V i}-\bar{s}_{V}}\right)\left[\left(s_{V i} \cdot \frac{\operatorname{Cov}\left(d g, d g_{i}\right)}{\operatorname{Var}(d g)}-s_{V i}\right)-\left(\sum_{k} w_{k} s_{V k} \frac{\operatorname{Cov}\left(d g, d g_{k}\right)}{\operatorname{Var}(d g)}-\sum_{k} w_{k} s_{V k}\right)\right]
$$

With some algebraic manipulation, and noting that $\sum_{k} w_{k} s_{V k}$ equals $\bar{s}_{V}$, we find:

$$
\operatorname{plim} \frac{\phi_{i}}{\phi}=\left[\frac{s_{V i} \cdot \gamma_{i}-\sum_{k} w_{k} s_{k} \gamma_{k}}{s_{V i}-\bar{s}_{V}}\right]
$$

where $\gamma_{i}$ is the (asymptotic) coefficient from a regression of $d g_{i}$ on $d g$ : $\operatorname{Cov}\left(d g, d g_{i}\right) / \operatorname{Var}(d g)$.

By assuming that aggregate $d g$ is appropriate when it is not, regression (22) in essence suffers from omitted variable bias, with the bias given by equation (25). Equivalently, the regression disturbance term may be correlated with government capital. The bias depends on both the misspecification of industry productivity, and the misspecification of aggregate productivity. These misspecifications depend on how well $s_{V l} d g$ proxies for $s_{V i} d g_{i}$, which in turn depends on the $\gamma_{i}$. There is no bias if the industry-specific road stocks are not systematically different from the aggregate road stocks, since the $\gamma_{i}$ then equal 1 .

In other words, industry road growth matches aggregate road growth if there are no systematic differences in regional growth rates of roads, or if industries are distributed evenly across regions. Of course, an unequal regional distribution of industries can contribute to unequal regional road growth, if regional road growth responds more strongly to productivity growth of industries in that region. 
To get a sense for the potential magnitude of this bias, I performed some simple simulations. Morrison and Schwartz (1996, Table 2) provide growth in public capital for four regions of the country from 1971 to $1987 .{ }^{19}$ In all regions, the growth rate fell, but it fell much faster than average in the east, and much

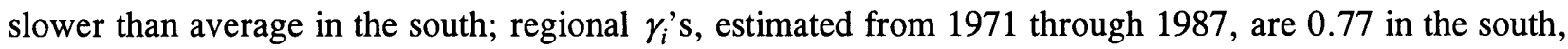
0.84 in the north, 1.06 in the west, and 1.71 in the east. Suppose there are four industries, each producing in a separate region, and each of which is the same size (using the actual regional distribution of production for 1977 , from BEA data, gives virtually identical results), and that the average vehicle share is 1.5 percent. The table shows the industry biases, for several combinations of industry vehicle intensities.

\begin{tabular}{|c|c|}
\hline $\begin{array}{c}\text { Vehicle shares (South, North, East, and West) } \\
\text { (percent) }\end{array}$ & $\begin{array}{c}\text { plim }(\Phi / \phi) \\
\text { (South, North, East, and West) }\end{array}$ \\
\hline$(1.4,1.4,1.81 .4)$ & $(5.5,4.6,4.4,3.0)$ \\
\hline$(1.6,1.6,1.2,1.6)$ & $(-2.8,-1.9,-1.6,0.0)$ \\
\hline$(1.0,1.0,3.0,1.0)$ & $(2.1,2.0,2.0,1.8)$ \\
\hline$(1.9,1.9,0.3,1.9)$ & $(0.3,0.6,0.7,1.1)$ \\
\hline
\end{tabular}

The bias can be very large, even though the correlations between the regional growth rates and the aggregate growth rate is generally above 0.9 . In several cases, not only is the bias negative (a ratio less than one), but the actual sign of the estimated coefficient is reversed. The sign is ambiguous, since it depends on the sign of $\left(s_{V i}-\bar{s}_{V}\right)$. The magnitude of the bias also depends heavily on $\left(s_{V i}-\bar{s}_{V}\right)$. The bias tends to be positive if industries with above-average $\gamma_{i}$ also have above-average vehicle shares; also, the bias is larger in the first two rows, where the deviations of vehicle intensities from the average are relatively small, than in the second two rows, where the deviations of vehicle intensities are larger.

19 These data, originally from Munnell (1990), are for all government capital, not just roads. Holtz-Eakin (1994a) describes estimates of regional road stocks, but provides insufficient detail for these simulations. However, regional road growth was probably similar to the growth in all government capital. In any case, the simulations reported here are meant only to be suggestive, since estimates of regional public capital are not available for the full sample period, and probably suffer substantial measurement error. The estimates involve allocating national capital stocks to regions, based on various proxies for regional expenditure. For example, Holtz-Eakin estimates benchmark state capital stocks for 1960 by allocating the national capital stock based on the states' shares of total current government expenditures in 1960. Errors in this benchmark would significantly affect estimates of industry-specific government capital stocks. 
In practice, of course, industry road stocks vary less than in this example, since industries are not completely segmented by region. Therefore, I estimated industry-specific government capital stocks, using BEA data on the regional distribution of production in 1977 , for the four regions for which I have government capital data. I then assess the magnitude of the bias from equation (25). Although I do not have the data to estimate industry-specific government capital for the entire sample period, this exercise gives me a metric to assess whether I can safely ignore the regional distribution of industries.

From 1971 to 1987 , the correlation of growth rates for industry and aggregate government capital is always above 0.99 . Inserting the sample variances and covariances into the bias equation (25) for each of the 27 private industries (all private industries, excluding agriculture, mining, tobacco, and petroleum refining), the median bias ratio is 0.88 ; the interquartile range is 0.82 to 1.01 . For the nine one-digit SIC industries, the median bias was 1.04. For both groupings, there were two particular outliers: Trade (8.2), and Services $(-0.95)$. The cause of the substantial bias ratio is that these two industries have vehicle-shares that are particularly close to the aggregate vehicle share, and hence, as equation (25) shows, the bias ratio can easily be very large.

We cannot estimate the bias ratio for the entire sample, since regional public capital is not available earlier. Assuming that in the earlier period, the regional variation in public capital growth rates was similar to the variation in the later period, the appropriate interpretation of these results would seem to be that at the one- and two-digit data, there is sufficient regional variation in the industries to allow for a bias (positive or negative) on the order of 10 percent, though for some individual industries it may be much larger.

Nevertheless, the results suggest that by judicious aggregation, we can reduce both bias (by ensuring an adequate distribution of regional production) and standard errors (by increasing the deviation of vehicle shares from the average, hence increasing the variation in the right-hand-side regressor).

I aggregated industries in order to ensure an appropriate distribution for $\left(s_{V i}-\bar{s}_{V}\right) .{ }^{20}$ In and of itself, this aggregation over heterogeneous industries tends to smooth regional differences in industry location, and

${ }^{20}$ Note that choosing the "optimal" industry aggregates for this problem would be very difficult. For example, we could not simply seek to minimize the regional differences in industry distribution, since that would not ensure that the vehicle shares differ by enough from the aggregate to allow precise and unbiased estimates. More importantly, the bias ratio for an industry depends on the covariance of industry and aggregate government capital growth for every other industry. 
hence reduce the potential bias. I followed an informal lexicographic ordering, seeking first to maximize the minimum absolute value of the deviation from the average share; and then seeking to minimize the variation in the deviation. The nine groupings, aggregated using Tornquist indices, are as follows: ${ }^{21}$

\begin{tabular}{c|l} 
Grouping & \multicolumn{1}{|c}{ Industries } \\
\hline 1 & Electric and Gas Utilities, Services \\
2 & $\begin{array}{l}\text { Construction, Stone-Clay-Glass, Communications } \\
\text { Transport, Trade, Lumber } \\
3\end{array}$ \\
4 & Autos, Industrial Machinery, FIRE \\
5 & Furniture, Leather, Primary Metals \\
6 & Paper, Food, Electronic Equipment \\
7 & Apparel, Printing, Misc. Manufacturing \\
8 & Textiles, Rubber, Fabricated Metals \\
9 & Chemicals, Other Transport Equipment, Instruments \\
\hline
\end{tabular}

To assess the equality of the spatial distribution, I perform the same simulation as above, calculating industry government capital growth from 1971 to 1987 , and then inserting the sample variances and covariances into the bias ratio formula (25). For my final grouping into nine aggregates, the median bias ratio was 0.97 , and none of the groups was far from unity.

The industry aggregates do not, of course, have any natural economic interpretation in the way that, say, one-digit SIC groupings would. With perfect competition and constant returns, however, this aggregation does not lead to any biases in my estimating equation, since productivity residuals aggregate cleanly under these conditions. As discussed in Section I, deviations from perfect competition and constant returns are unlikely to have a major effect on the estimates.

${ }^{21}$ I also experimented with including a tenth grouping of Petroleum Products and Tobacco. The argument for including them is to have as much data as possible; the argument for excluding them is that they are unusually volatile, and are often considered suspect. I excluded them to ensure that these suspect industries do drive results. However, results are not much affected in any case. 


\section{BIBLIOGRAPHY}

Aschauer, David Alan (1989). "Is Public Expenditure Productive?" Journal of Monetary Economics 23: 177-200.

Aschauer, David Alan (1990). "Why is Infrastructure Important?" in Munnell, Alicia ed., Is There a Shortfall in Public Capital Investment? Federal Reserve Bank of Boston Conference Series No. 34.

Barro, Robert J. and Xavier Sala-i-Martin (1995). Economic Growth, chapter 4. McGraw-Hill, Inc., New York.

Basu, Susanto and John Fernald (1995a). "Are Apparent Productive Spillovers a Figment of Specification Error?" Journal of Monetary Economics 36:165-188.

Basu, Susanto and John Fernald (1997). "Returns to Scale in U.S. Production: Estimates and Implications." Journal of Political Economy, April.

Basu, Susanto and Miles Kimball (1997). “Cyclical Productivity with Unobserved Input Variation.” NBER Working Paper 5915.

Berndt, Ernst R. and Bengt Hansson (1992). "Measuring the Contribution of Public Infrastructure Capital in Sweden." Scandinavian Journal of Economics, 94, Supplement, 151-168.

Boskin, Michael, Marc Robinson, and Alan Huber (1989). "Government Saving, Capital Formation, and Wealth in the United States, 1947-85." in Lipsey and Tice, The Measurement of Saving, Investment, and Wealth.

Congressional Budget Office (1991). How Federal Spending for Infrastructure and Other Investments Affects the Economy.

Federal Highway Administration. Highway Statistics, various years.

Ford, Robert and Pierre Poret (1991). "Infrastructure and Private-Sector Productivity." OECD Working Paper 91, January.

Gramlich, Edward M. (1994). "Infrastructure Investment: A Review Essay." Journal of Economic Literature, XXXII:1176-1196.

Hall, Robert (1990). "Invariance Properties of Solow's Productivity Residual." in Peter Diamond, ed., Growth/Productivity/Unemployment: Essays to Celebrate Bob Solow's Birthday. MIT Press.

Hall, Robert and Dale Jorgenson (1967). "Tax Policy and Investment Behavior." American Economic Review 57:3, June, 391-414.

Holtz-Eakin, Douglas (1994a). "Public-Sector Capital and the Productivity Puzzle." Review of Economics and Statistics.76:12ff.

Holtz-Eakin, Douglas (1994b). "State-Specific Estimates of State and Local Government Capital.” Regional Science and Urban Economics 23: 185-209. 
Hulten, Charles and Frank C. Wykoff (1981). "The Measurement of Economic Depreciation," in C. Hulten, ed., Depreciation, Inflation, and the Taxation of Income from Capital.

Hulten, Charles and Robert M Schwab (1991). "Public Capital Formation and the Growth of Regional Manufacturing Industries." National Tax Journal, 44(4), Part 1: 121-34.

Hulten, Charles (1994). "Optimal Growth with Infrastructure Capital: Theory and Implications for Empirical Modeling." Manuscript, University of Maryland.

Jorgenson, Dale and Frank M. Gollop and Barbara M. Fraumeni (1987). Productivity and U.S. Economic Growth. Harvard University Press, Cambridge, MA.

Jorgenson, Dale and Kun-Yung Yun (1990). Tax Reform and the Cost of Capital.

Kocherlakota, Narayana and Kei-Mu Yi (1996). "A Simple time Series Test of Endogenous vs. Exogenous Growth Models: An Application to the United States." Review of Economics and Statistics.

Mankiw, N. Gregory (1992). "The Optimal Underprovision of Public Goods." Mimeo, Harvard University.

Morrison, Catherine J. and Amy Ellen Schwartz (1996). "State Infrastructure and Productive Performance." American Economic Review (December).

Munnell, Alicia ed. (1990). "How Does Public Infrastructure Affect Regional Economic Performance?" in Munnell, ed., Is There a Shortfall in Public Capital Investment? Federal Reserve Bank of Boston Conference Series No. 34.

Nadiri, M. Ishaq and Theofanis P. Mamuneas (1994). "The Effects of Public Infrastructure and R\&D Capital on the Cost Structure and Performance of U.S. Manufacturing Industries." Review of Economics and Statistics 76(1):22-37.

Small, Kenneth, Clifford Winston, and Carol Evans (1989). Road Work. Brookings: Washington, DC.

U.S. Department of Commerce, Bureau of Economic Analysis (1993). Fixed Reproducible Tangible Wealth in the United States, 1929-1989. US Government Printing Office, Washington, DC.

U.S. Department of Commerce, Bureau of Economic Analysis (1995). "Wealth Data Diskettes."

Wolff, Edward N (1996). "The Productivity Slowdown: The Culprit at Last? Follow-Up on Hulten and Wolff." American Economic Review (December) 86:1239-1252. 
Table 1

Value-Added Productivity Growth and Vehicle Shares by Industry, 1953-1989

\begin{tabular}{|c|c|c|c|c|c|}
\hline Industry & $\begin{array}{c}\text { Average } \\
\text { TFP } \\
\text { Growth } \\
(1) \\
\end{array}$ & $\begin{array}{c}\text { TFP } \\
\text { Growth } \\
1953-73 \\
(2) \\
\end{array}$ & $\begin{array}{c}\text { TFP } \\
\text { Growth } \\
1973-89 \\
(3)\end{array}$ & Change & $\begin{array}{c}\text { Average } \\
\text { Vehicle } \\
\text { Share } \\
(5) \\
\end{array}$ \\
\hline Transportation & 1.8 & 2.5 & 1.0 & -1.4 & 5.5 \\
\hline Gas Utilities & -0.7 & 1.7 & -4.2 & -5.9 & 4.8 \\
\hline Stone, clay, glass & 0.9 & 1.1 & 0.9 & -0.2 & 2.8 \\
\hline Communications & 2.8 & 2.7 & 3.0 & 0.3 & 2.6 \\
\hline Construction & 0.6 & 1.3 & -0.7 & -2.0 & 2.2 \\
\hline Electric Util & 2.2 & 3.7 & 0.0 & -3.7 & 2.2 \\
\hline Lumber \& wood & 1.5 & 1.0 & 1.5 & 0.6 & 1.7 \\
\hline Trade & 1.3 & 1.9 & 0.3 & -1.5 & 1.7 \\
\hline Services & 0.2 & 0.7 & -0.5 & -1.2 & 1.5 \\
\hline Food \& kindred products & 2.5 & 3.1 & 1.3 & -1.8 & 1.3 \\
\hline F.I.R.E. & 0.4 & 0.6 & 0.0 & -0.7 & 1.1 \\
\hline Petroleum products & 5.6 & -1.2 & 11.6 & 12.8 & 1.0 \\
\hline Paper products & 1.0 & 1.8 & 0.4 & -1.4 & 0.9 \\
\hline Chemicals & 3.0 & 4.9 & 0.7 & -4.2 & 0.7 \\
\hline Primary metals & -0.8 & -0.1 & -1.5 & -1.4 & 0.6 \\
\hline Furniture and fixtures & 1.6 & 1.4 & 1.8 & 0.5 & 0.6 \\
\hline Printing \& publishing & -0.1 & 1.0 & -1.6 & -2.6 & 0.6 \\
\hline Tobacco products & -0.2 & 1.5 & -1.3 & -2.8 & 0.5 \\
\hline Fabricated metals & 1.1 & 1.3 & 1.2 & -0.1 & 0.5 \\
\hline Electronic equipment & 3.3 & 3.1 & 3.7 & 0.6 & 0.5 \\
\hline Motor vehicles & 1.7 & 2.8 & 0.5 & -2.4 & 0.4 \\
\hline Misc. manufacturing & 3.0 & 3.1 & 2.6 & -0.6 & 0.4 \\
\hline Instruments and related & 2.2 & 2.4 & 1.9 & -0.4 & 0.4 \\
\hline Apparel \& textile & 3.8 & 3.3 & 4.8 & 1.5 & 0.3 \\
\hline Industrial machinery & 2.3 & 1.0 & 4.7 & 3.7 & 0.3 \\
\hline Other transport. equip. & 1.3 & 1.1 & 1.5 & 0.4 & 0.3 \\
\hline Textile mill products & 3.7 & 2.7 & 4.1 & 1.4 & 0.3 \\
\hline Rubber \& plastics & 1.7 & 2.6 & 0.6 & -2.1 & 0.2 \\
\hline Leather products & 1.0 & 0.0 & 2.8 & 2.8 & 0.2 \\
\hline Economy Average & 1.0 & 1.6 & 0.3 & -1.3 & 1.6 \\
\hline Std. Deviation & 1.4 & 1.3 & 2.8 & 3.2 & 1.3 \\
\hline
\end{tabular}


Table 2

Basic Results

\begin{tabular}{|c|c|c|c|c|c|c|c|c|}
\hline & \multicolumn{2}{|c|}{$\begin{array}{c}\text { Aggregated } \\
\text { Industries }\end{array}$} & \multicolumn{2}{c|}{$\begin{array}{c}\text { One-Digit } \\
\text { Industries }\end{array}$} & \multicolumn{2}{c|}{$\begin{array}{c}\text { Manufacturing } \\
\text { Industries }\end{array}$} & \multicolumn{2}{c|}{$\begin{array}{c}\text { Non- } \\
\text { Manufacturing } \\
\text { Industries }\end{array}$} \\
\cline { 2 - 9 } & $(1)$ & $(2)$ & $(3)$ & $(4)$ & $(5)$ & $(6)$ & $(7)$ & $(8)$ \\
\hline$\phi$ & 22.1 & $\begin{array}{c}17.4 \\
(4.0)\end{array}$ & $\begin{array}{c}22.9 \\
(3.6)\end{array}$ & $\begin{array}{c}19.3 \\
(4.3)\end{array}$ & $\begin{array}{c}36.0 \\
(2.7\end{array}$ & $\begin{array}{c}35.1 \\
(4.0)\end{array}$ & $\begin{array}{c}15.8 \\
(4.1)\end{array}$ & $\begin{array}{c}11.7 \\
(4.6)\end{array}$ \\
\hline$\phi_{73}$ & & $\begin{array}{c}-25.3 \\
(11.2)\end{array}$ & & $\begin{array}{c}-14.7 \\
(10.0)\end{array}$ & & $\begin{array}{c}-11.5 \\
(9.5)\end{array}$ & & -19.3 \\
& & & & & & & & \\
\hline
\end{tabular}

Note: Estimates of equation (9) from 1953-1989 (with standard deviations in parentheses). $\phi$ is the coefficient on roads, and $\phi_{73}$ is the change in the coefficient after 1973. The four industry groupings are described in the text. 
Table 3

Including Congestion Variables

\begin{tabular}{|c|c|c|c|c|c|c|}
\hline & (1) & (2) & (3) & (4) & (5) & (6) \\
\hline$\phi$ & $\begin{array}{l}23.5 \\
(4.0)\end{array}$ & $\begin{array}{r}14.6 \\
(4.6)\end{array}$ & $\begin{array}{l}14.1 \\
(5.5)\end{array}$ & $\begin{array}{l}17.4 \\
(4.2)\end{array}$ & $\begin{array}{l}13.7 \\
(5.5)\end{array}$ & $\begin{array}{l}18.1 \\
(4.0)\end{array}$ \\
\hline$\phi_{73}$ & & $\begin{array}{l}-12.7 \\
(11.4)\end{array}$ & & $\begin{array}{c}-9.3 \\
(14.4)\end{array}$ & $\begin{array}{c}-6.9 \\
(14.5)\end{array}$ & \\
\hline$\kappa$ & $\begin{array}{c}2.7 \\
(4.3)\end{array}$ & $\begin{array}{c}-3.8 \\
(4.1)\end{array}$ & $\begin{array}{c}-5.2 \\
(5.1)\end{array}$ & & $\begin{array}{c}-5.0 \\
(5.2)\end{array}$ & \\
\hline$\kappa_{73}$ & & & $\begin{array}{l}10.1 \\
(4.5)\end{array}$ & $\begin{array}{c}5.7 \\
(4.6)\end{array}$ & $\begin{array}{c}8.5 \\
(5.6)\end{array}$ & $\begin{array}{c}7.6 \\
(3.8)\end{array}$ \\
\hline
\end{tabular}

Note: Standard deviations in parentheses. $\phi$ is the coefficient on roads, and $\phi_{73}$ is the change in the coeffient after 1973. $\kappa$ is the coefficient on congestion, and $\kappa_{73}$ is the change in the congestion coefficient after 1973 (a positive number signifies an increase in congestion). 
Table 4

Using Roads before 1973, Roads/Miles after 1973

\begin{tabular}{|c|c|c|}
\hline & $(1)$ & $(2)$ \\
\hline$\phi_{\text {Post73 }}$ & 17.1 & 18.7 \\
& $(3.1)$ & $(7.4)$ \\
\hline$\phi_{\text {Post73 }}$ & 5.3 & 6.0 \\
& $(4.5)$ & $(5.0)$ \\
\hline $\begin{array}{c}\text { Includes Post-73 Industry } \\
\text { Dummies? }\end{array}$ & No & Yes \\
\hline
\end{tabular}

Note: Standard deviations in parentheses. 
Figure 1

Roads and Miles-Driven (Per Capita)

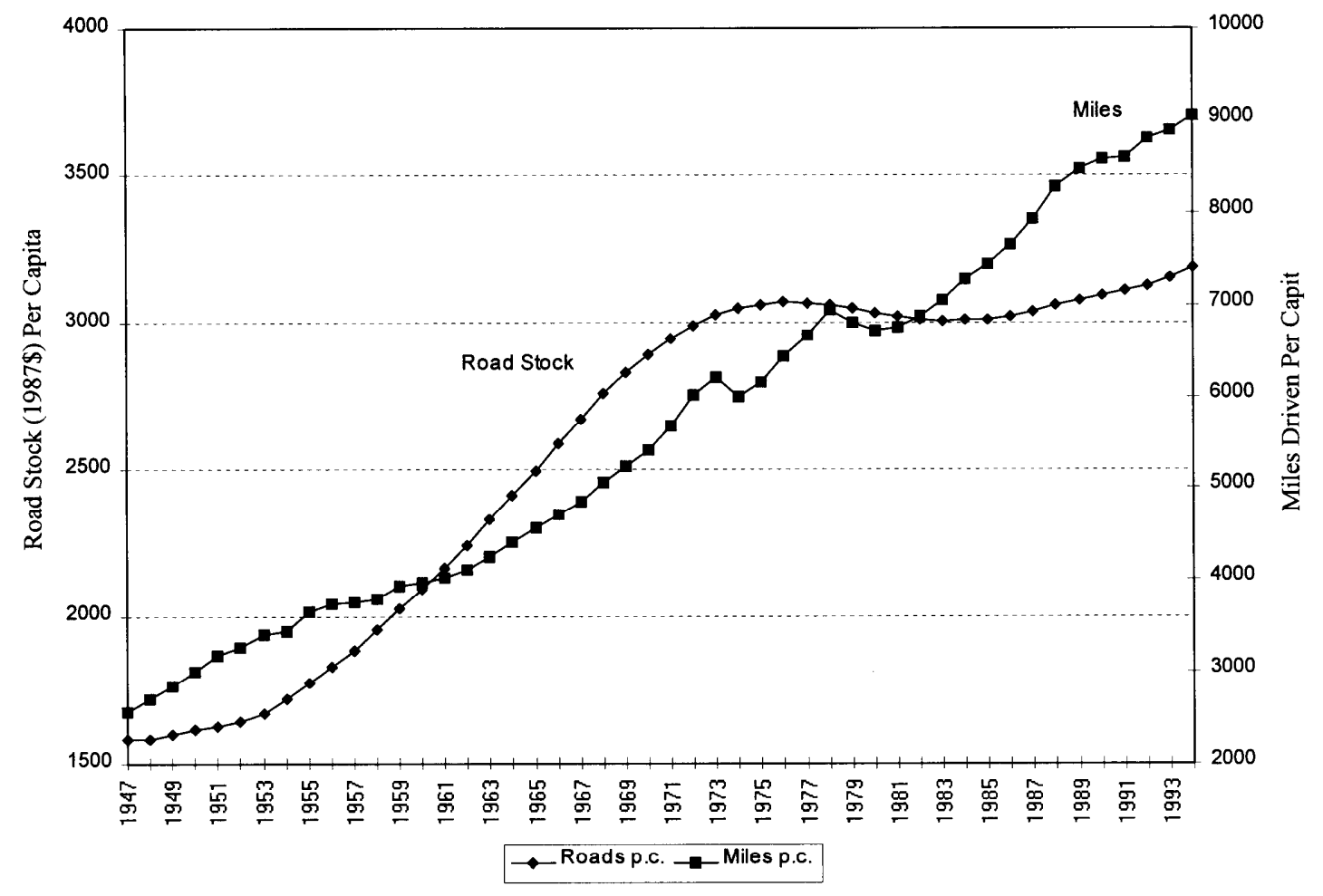


Figure 2

Change in Total Factor Productivity after 1973 v. Vehicle Share

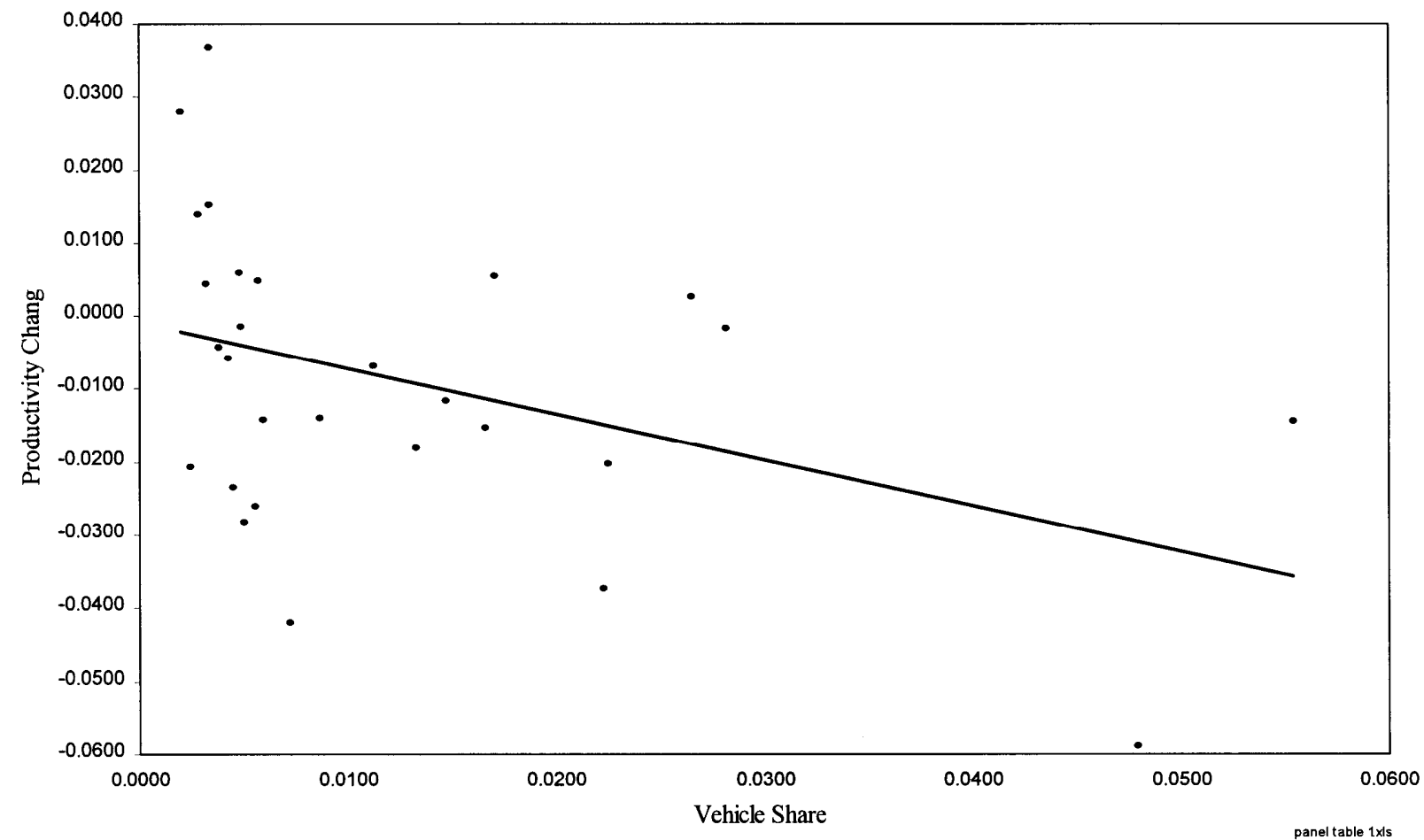

